\title{
Aortic root thrombosis after transhiatal esophagectomy: A case report
}

\author{
Tomasz A. Timek, MD, ${ }^{a}$ Craig T. Alguire, MD, ${ }^{a}$ Kevin G. Wolschleger, MD, ${ }^{a}$ and Mathew H. Chung, MD, \\ Grand Rapids, Mich
}

Ascending aortic thrombosis is a rare clinical entity with potential lethal consequences, yet forms of therapy are not uniform. We present the clinical course of a patient who developed aortic root thrombus after transhiatal esophagectomy for an esophageal malignancy.

\section{CLINICAL SUMMARY}

A 52-year-old man with history of tobacco abuse and esophageal adenocarcinoma initially treated with neoadjuvant chemoradiation presented to our emergency department with left hand weakness and ataxia 3 weeks after transhiatal resection of the esophagus. The patient's symptoms resolved in the emergency department, he received $325 \mathrm{mg}$ aspirin, and initial computed tomography (CT) scan of the patient's head did not reveal abnormalities, neither did a carotid duplex ultrasound test. Magnetic resonance imaging (MRI) scans, however,

From the Meijer Heart and Vascular Institute, ${ }^{a}$ Grand Rapids Medical Education Partners, and Spectrum Health Medical Group, ${ }^{\mathrm{b}}$ Grand Rapids, Mich.

Disclosures: Authors have nothing to disclose with regard to commercial support.

Received for publication Aug 26, 2012; accepted for publication Oct 22, 2012; available ahead of print Nov 9, 2012.

Address for reprints: Tomasz A. Timek, MD, Meijer Heart and Vascular Institute at Spectrum Health, 100 Michigan Ave NE, Grand Rapids, MI 49503 (E-mail: timek@wmcts.com).

J Thorac Cardiovasc Surg 2013;145:e14-6

$0022-5223 / \$ 36.00$

Copyright $(c) 2013$ by The American Association for Thoracic Surgery

http://dx.doi.org/10.1016/j.jtcvs.2012.10.035 confirmed embolic stroke in the right middle cerebral artery distribution consistent with the patient's symptoms. Workup of potential embolic sources included a transthoracic echo, which revealed an echogenic density in the noncoronary sinus of the aortic root suggestive of thrombus. The aortic valve was trileaflet and without stenosis or regurgitation. CT angiogram of the chest confirmed aortic root thrombus (Figure 1) and evidence of embolus in the left hepatic artery as well as splenic infarcts. The thoracic aorta appeared normal sized without evidence of calcifications or ulcerations. These findings were not present on preoperative imaging before the esophagectomy. Immediate anticoagulation therapy was started with heparin and follow-up MRI scan after 4 days (Figure 2) showed the thrombus to be stable and approximately $37 \times 28 \times 16 \mathrm{~mm}$ in size. No other aortic pathology was noted. The patient remained asymptomatic and surgical extraction of the thrombus was considered, but he was unwilling to proceed in light of the recent esophagectomy. Hypercoagulable workup was intiated and the patient was subsequently transitioned to warfarin and discharged to home on hospital day 5. One week after discharge, the patient represented to the emergency department with acute right lower extremity pain and numbness distal to the knee with a cool extremity and no palpable distal pulses. International normalized ratio was therapeutic at 3.6. CT angiogram revealed the aortic root thrombus to be no longer present (Figure 3) with
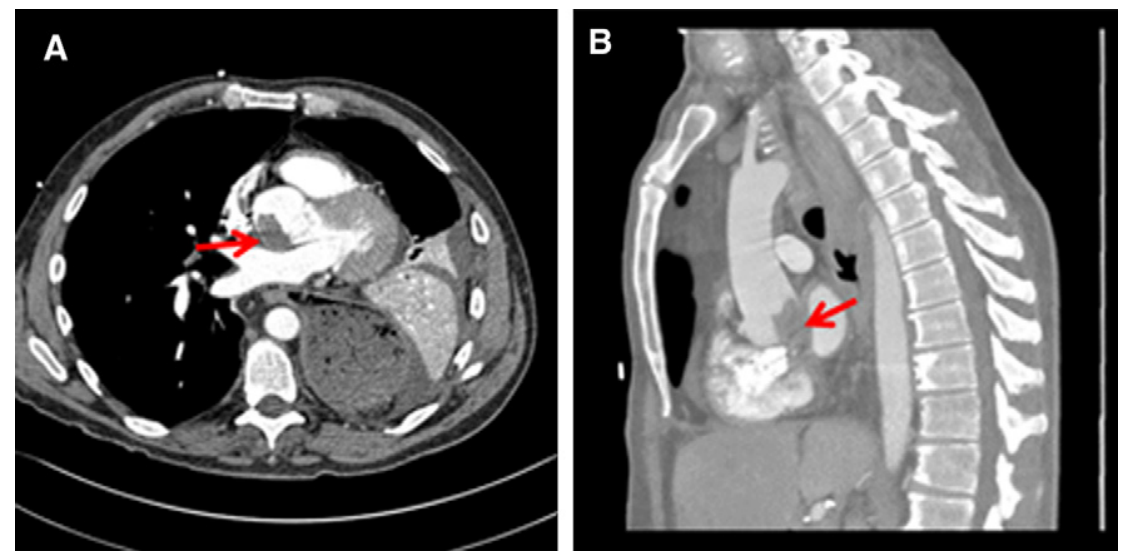

FIGURE 1. A, Computed tomography scan of the patient's chest on initial admission demonstrating extensive aortic root thrombus on axial views of the ascending aorta. B, Computed tomography scan of the patient's chest on initial admission demonstrating extensive aortic root thrombus on saggital views of the ascending aorta. Red arrows delineate the position of the aortic root thrombus. 


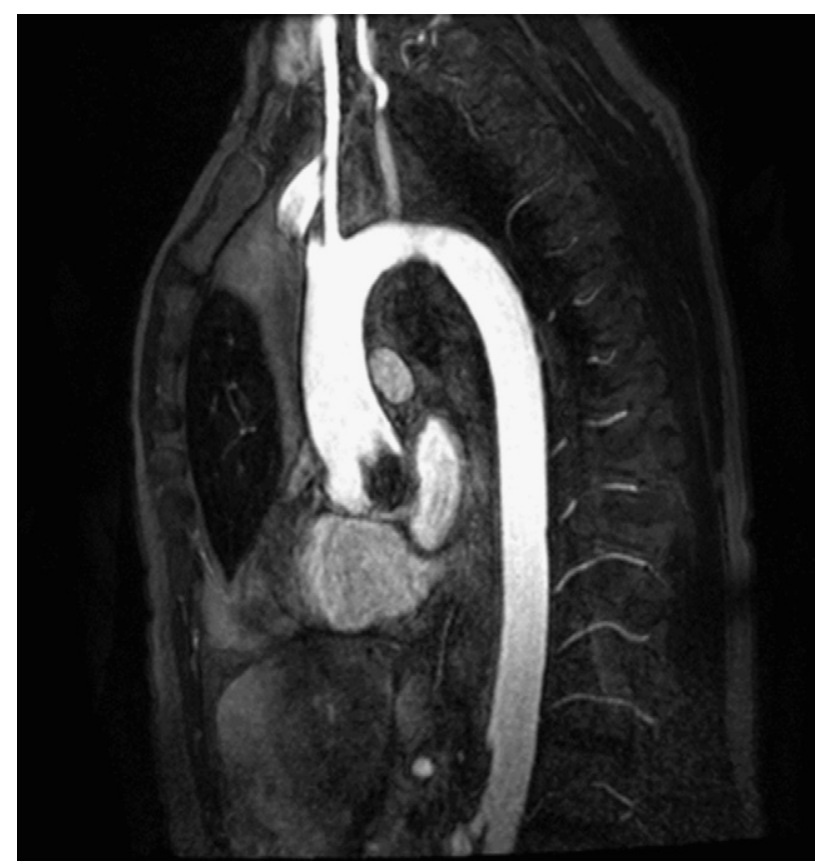

FIGURE 2. Sagittal magnetic resonance imaging view of the entire thoracic aorta 4 days after the patient's admission to the hospital, showing stable size of aortic root thrombus following initiation of anticoagulation therapy and no other abnormalities within the thoracic aorta.

multiple new emboli in the abdomen, pelvis, and lower extremities, including the right common and superficial femoral arteries. The patient underwent emergent femoral thromboembolectomy, recovered uneventfully, and continues to receive anticoagulant therapy. Genetic and hematologic testing for hypercoagulable state was unrevealing.

\section{DISCUSSION}

Ascending aortic thrombus has been reported in the literature in patients with malignancies, particularly after cisplatin-based chemotherapy. ${ }^{1,2}$ Root thrombosis has been described to result in myocardial infarction ${ }^{3}$ or intermittent ischemia. ${ }^{4}$ The clinical treatment of this potentially fatal entity has not been uniformly defined, with both conservative ${ }^{1,2}$ and surgical ${ }^{5,6}$ management being advocated. We describe a patient with multiple risk factors for hypercoagulability who developed the unusual complication of aortic root thrombosis after transhiatal esophagectomy. Recent surgery, history of malignancy, chemotherapy, and tobacco use are clear identifiable risk factors, yet the mechanical effect of transhiatal approach on the geometry of the aortic root must also be considered. It is feasible that local factors and a hypercoagulable milieu contributed to the formation of thrombus in an area of high flow. To our knowledge, this is the first case in the literature of

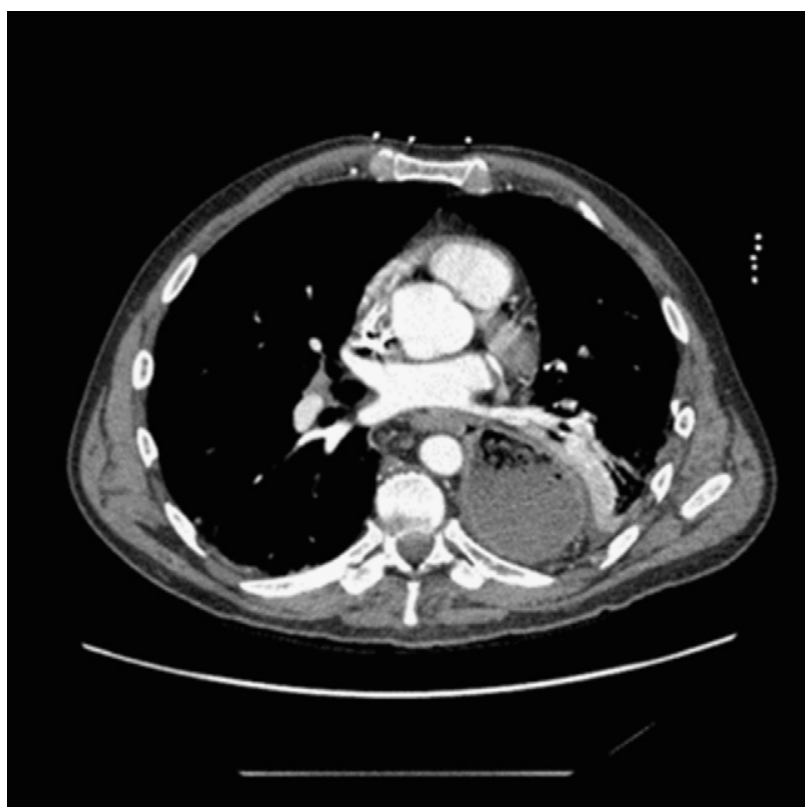

FIGURE 3. Computed tomography scan of the patient's chest on readmission to the hospital for acute lower extremity ischemia. Axial image shows resolution of aortic root thrombus with normal root morphology.

aortic root thrombosis after esophageal resection. Based on this anecdotal experience and a published small single-center series, ${ }^{7}$ we advocate early surgical intervention in selected patients because therapeutic anticoagulation does not appear to be protective. The aortic root is a dynamic structure with torsional deformation, ${ }^{8}$ and therefore even if no local effect on coronary perfusion is present, the risk of embolization can be presumed to be significant.

This is exemplified by our patient, who upon return to the hospital had evidence of diffuse embolization while receiving therapeutic anticoagulation medication. Although successful conservative therapy with anticoagulation agents has been described in patients with ascending aortic thrombosis, those patients were poor surgical candidates with metastatic lung malignancies. On the other hand, extraction of aortic thrombus appears to have low mortality and effectively prevents recurrent embolization. ${ }^{7}$ As such, appropriate surgical candidates who develop aortic root thrombus should be offered intervention early to prevent possible devastating consequences of continued embolization.

\section{References}

1. Chin SO, Lee JJ, Hwang YH, Han JJ, Maeng CH, Baek SK, et al. Aortic thrombosis resolved with enoxaparin in a patient treated with cisplatin-based regimen for small cell lung cancer. Int J Hematol. 2010;91:892-6.

2. Hahn SJ, Oh JY, Kim JS, Kim DY. A case of acute aortic thrombosis after cisplatinbased chemotherapy. Int J Clin Oncol. 2011;16:732-6. 
3. Tamura T, Iwasaki H, Ikuta T, Fujil H, Okuda H, Nishimura S, et al. Successful treatment of myocardial infarction by aortic sinus thrombosis. Ann Thorac Surg. 2011;92:e43-5.

4. Hisatomi K, Yamada T, Odate T, Yamashita K. Intermittent coronary artery occlusion caused by floating thrombus in the left coronary sinus of valsalva of a patient with a normal aorta and protein C deficiency. Ann Thorac Surg. 2011;92: 1508-10.

5. Sawada T, Shimokawa T. Giant thrombus in the ascending aorta that caused systemic embolism. Interact Cardiovasc Thorac Surg. 2011;12:1048-50.
6. Calderon P, Heredero A, Pastor A, Higueras J, Hernandez J, Karagounis PA, et al. Successful removal of a floating thrombus in ascending aorta. Ann Thorac Surg. 2011;91:e67-9.

7. Pagni S, Trivedi J, Ganzel B, Williams M, Kapoor N, Ross C, et al. Thoracic aortic mobile thrombus: is there a role for early surgical intervention. Ann Thorac Surg. 2011;91:1875-81.

8. Dagum P, Green GR, Nistal FJ, Daughters GT, Timek TA, Foppiano LE, et al. Deformational dynamics of the aortic root: modes and physiologic determinants. Circulation. 1999; 100(Suppl):II54-62.

\section{Subcostal to rib-cross incision for HeartMate II explantation: A case report}

Takashi Nishimura, MD, Takeyoshi Ota, MD, PhD, Hiroo Takayama, MD, PhD, and Yoshifumi Naka, MD, PhD, New York, NY

The role of left ventricular assist devices (LVADs) is expected to become more important because of an increasing number of patients experiencing heart failure and a shortage heart transplant donors. ${ }^{1}$ LVAD explantation following myocardial recovery is well documented ${ }^{2}$ and most of the patients requiring the procedure have multiple medical problems, making minimally invasive methods more attractive. Several surgical approaches have been reported. ${ }^{3,4} \mathrm{We}$ report 2 cases of LVAD explantation using a subcostal to rib-cross incision combined with a separate anteriolateral minithoracotomy.

\section{CLINICAL SUMMARY}

The first patient was 57 years old and had a HeartMate II (Thoratec, Pleasanton, Calif) LVAD implant for cardiogenic shock after redo aortic valve replacement. The patient's ejection fraction (EF) improved from $15 \%$ to $45 \%$ over 2 months and the LVAD was explanted 64 days after LVAD implantation. The second patient was 47 years old and had an HeartMate II LVAD implant for cardiogenic shock after coronary artery bypass grafting and mitral valve repair. The EF in this patient improved from $10 \%$ to $60 \%$ over 5 months and the LVAD was explanted 149 days after it had been implanted.

A subcostal incision was made over the device and extended laterally toward the rib cage to match placement of

From the Division of Cardiothoracic Surgery, Columbia University, New York, NY. Disclosures: Authors have nothing to disclose with regard to commercial support. Received for publication Sept 9, 2012; revisions received Oct 3, 2012; accepted for publication Oct 22, 2012; available ahead of print Nov 12, 2012.

Address for reprints: Takashi Nishimura, MD, 177 Fort Washington Ave, Milstein 7GN-435, New York, NY 10032 (E-mail: takishi@hotmail.com).

J Thorac Cardiovasc Surg 2013;145:e16-7

0022-5223/\$36.00

Copyright (C) 2013 by The American Association for Thoracic Surgery

http://dx.doi.org/10.1016/j.jtcvs.2012.10.036 the device. The apex of the heart and the device inflow was exposed by excising the seventh rib. The upper side of the costal incision was retracted for exposure (Figure 1, A). Simultaneously, a small right thoracotomy through the third intercostal space was performed and the outflow graft was exposed (Figure 1, B). Cardiopulmonary bypass (CPB) was established from the right femoral artery (BioMedicus 17Fr cannula, Medtronic, Minneapolis, Minn) and vein (Biomedicus 21Fr cannula, Medtronic) (Figure 2). The left ventricular vent was not placed. The LVAD flow was discontinued and the outflow graft was clamped as soon as CPB was started. While in Trendelenburg position, the apical inflow cannula was removed. A left ventricular plug made from rolled felt was inserted into the left ventricular apical cuff and secured using no. 5 TiCron sutures (Covidien, Mansfield, Mass) and reinforced with Bioglue (CryoLife, Kennesaw, Ga) on its end. The outflow graft, which had been clamped since CPB started, was used as a root vent to deair by periodically opening the clamp. The $\mathrm{CPB}$ was weaned and came off followed by protamine reverse (CPB time 17 minutes and 49 minutes, respectively). The outflow graft was stapled and transected using a white vascular EndoGIA (Covidien) through the minithoracotomy. The bend relief was removed through the subcostal incision. Blake silicone drains (19Fr; Ethicon, Somerville, NJ) were placed in right pleural space, the outflow graft tunnel, and the device pocket. The incisions were closed in the standard fashion. Postoperative bleeding was minimal and the postoperative course was uneventful for both patients.

\section{DISCUSSION}

There are about 5 million patients with heart failure in the United States. Heart transplantation has been limited by the number of donors and has reached a plateau at about 4500 